\title{
INDIRECT PAYLOAD ESTIMATION IN CABLE-LOGGING OPERATIONS
}

\author{
Filippo Guerra ${ }^{1}$, Luca Marchi ${ }^{2}$, Stefano Grigolato ${ }^{2}$, Raimondo Gallo ${ }^{1}$ \\ ${ }^{1}$ Free University of Bozen, Italy; ${ }^{2}$ University of Padova, Italy \\ filippo.guerra@natec.unibz.it, luca.marchi@unipd.it, stefano.grigolato@unipd.it, \\ raimondo.gallo@unibz.it
}

\begin{abstract}
The paper proposes a novel technique to estimate the payload to which a cable system is loaded, from the analysis of the cable deflection occurring in the outhaul phases. The idea is to exploit a precision GNSS sensor to measure the difference of the vertical deflection between the outhaul phase with respect to the theoretical chord line connecting the two ends of the cable. A single-span downhill-oriented cable yarding system was used as case study. Continuous measurements of both mainline sag and tensile force combined with a theoretical model available from the literature allowed to estimate the given payload. The results show that the GNSS system was sufficiently precise to determine the cable deflection as the estimated and measured payloads were found to be positively correlated.
\end{abstract}

Keywords: forest mechanization; forest machine; cable-logging; GNSS system; precision forestry.

\section{Introduction}

The monitoring of forest operations is a topic of great interest because of the ever-increasing demand for the technical-economic evaluation as well as for the traceability of timber [1]. The productivity of a machine, a crew or a process is usually determined by the amount of product obtained in a well-defined period [2]. In cable logging, the collection of those data is usually carried out through manual time study and mass assessment procedures, operations that require enormous efforts in terms of time and safety for the staffs involved in it.

Nowadays, some experiences related to automatic motion study assessments have been already performed [3-5], but no researches about automatic hauled mass estimation are available. This topic is of gaining more interest, as knowing the hauled mass allows to assess both productivity of the harvesting system and the safety level of its structural components as cables, anchors and supports [6;7]. Available works about physic characteristics of yarding technologies are present in specific literature $[8 ; 9]$. The goal of this methodology is the mass assessment of the loaded biomass during the inhaul phase in cable logging operations. Following the study conducted by [10] on a scaled model, the approach was extended to a real cable yarding system. The theoretical approach proposed is based on the development and the use of a mathematical model available in the literature, which, thanks to the measurement of the skyline deflection, slope and tension, permits to estimate the hauled mass.

\section{Materials and methods}

Cable logging site used for this study was located in a mixed-spruce and beech stand forest in the municipality of Roana(Italy). The cable line was a single span downhill-oriented configuration, with the tower yarder located at the landing at the bottom of the stand, see Fig. 1. A truck-based cable yarder (Konrad Mounty 4000) and a hybrid motorized slack-pulling carriage (Bergwald 5000 Hybrid Power Plus) were used for yarding the logs. The monitored cable yarding system used a skyline with diameter equal to $20.5 \mathrm{~mm}$ (linear weight $=2.05 \mathrm{~kg} \cdot \mathrm{m}^{-1}$ ), and a mainline and haul back line with diameter equal to $11.0 \mathrm{~mm}$ (linear weight $=0.59 \mathrm{~kg} \cdot \mathrm{m}^{-1}$ ). Data collection was conducted for a complete working day, totaling 33 working cycles.

The recording of carriage movements and the consequent determination of the skyline vertical deflection was performed through a high accuracy GNSS device [3] mounted on the carriage. The device, MobileMapper ${ }^{\circledR} 120$ from Spectra Precision combined with MobileMapper Field proprietary software, was set to record single spatial points at $0.5 \mathrm{~Hz}$. The whole span connecting two different mountain slopes was completely free from tree crowns potentially interfering with GNSS signal.

The position of each structural element, including the tower yarder, anchor and tail spar, as well as the landing area were marked using a Garmin eTrex ${ }^{\circledR}$ 20. Then, a GIS software (ArcMap®version 10.5) was used to obtain the characteristic parameters of the land morphology by importing the positions of the elements of the line on the digital elevation model (DEM) of the cutting areas. Finally, 
the obtained lateral profile of the cable line is given in Fig. 2. Hauling operations were semi-suspended at the beginning and end of the travel and fully suspended in the portion of the cable line.

The total payload yarded in each cycle was determined by the processed log volume and assuming a wood density equal to $900 \mathrm{~kg} \mathrm{~m}^{-3}$ [11]. Dimensions of each transported log were obtained from the sensors included in the processing unit integrated in the cable yarder truck. The additional load of green wood, such as tree tops and branches, was visually estimated during the data collection adopting a crown coefficient according to[12].The weight of the carriage was assumed from the technical datasheet and set equal to $690 \mathrm{~kg}$.

The tensile forces of the skyline during the whole monitoring work were measured through a load cell) installed in proximity to the tail anchor. Measurements were performed continuously at a frequency of $100 \mathrm{~Hz}$ and down sampled in the post-processing phase with a moving mean algorithm to match the resolution of the GNSS system.

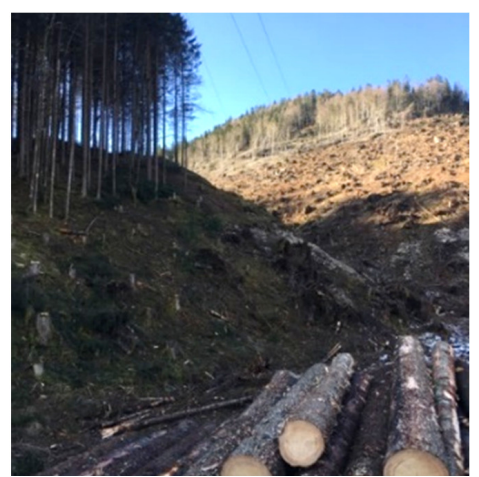

Fig. 1.View of harvesting site

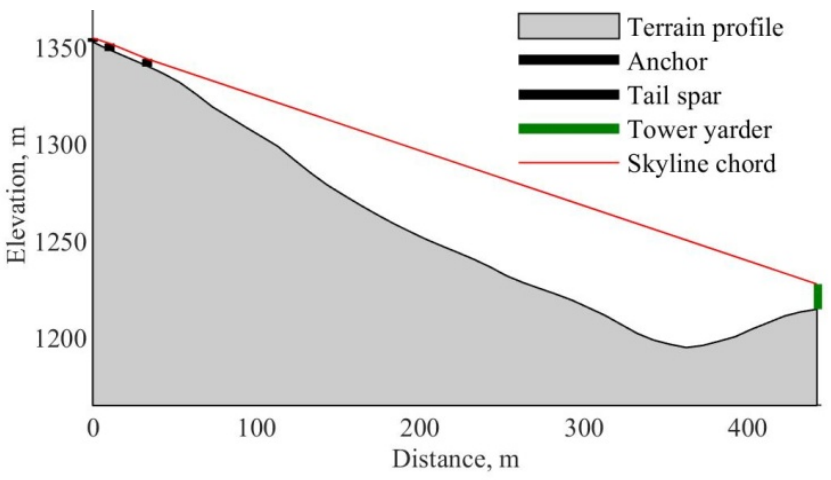

Fig. 2.Longitudinal profile

The analytical model used in this study followed the instructions given in [8], in which sag (or deflection) due to both the cable weight and the concentrated load is considered. Due to equilibrium of a cable system supposed to be pinned at both ends as shown in Fig. 3, the deflection $f_{x}$ at a given distance $x$ caused by an additional payload $\mathrm{Q}$ is given by the following equation:

$$
f_{x}=\frac{Q+\frac{1}{2} q \cdot L+\frac{1}{2} q_{2} \cdot L+\frac{1}{2}\left(q_{1}-q_{2}\right) \cdot x}{H} \cdot \frac{x \cdot(L-x)}{L}
$$

where $Q$-payload, $\mathrm{kN}$;

$q$ - linear weight of skyline, $\mathrm{kN} \cdot \mathrm{m}^{-1}$;

$q_{1}, q_{2}$ - linear weight of the mainline and haul-back line, $\mathrm{kN} \cdot \mathrm{m}^{-1}$;

$x$ - horizontal distance of the payload, $\mathrm{m}$;

$L$ - horizontal distance between the two ends of the line, $\mathrm{m}$;

$H$ - horizontal component of the tensile force applied on the skyline, $\mathrm{kN}$.

In this study all the above parameters have been collected during the survey. In particular, the horizontal component $H$ of the tensile force, was estimated from the tensile force $T$ measured by the load cell applying the trigonometric equation reported below:

$$
H=T \cdot \cos \left[\arctan \left(\frac{z+f_{x}}{x}\right)\right]
$$

where $T$ - measured tensile force on the cable, $\mathrm{kN}$;

$z$-vertical distance of the payload measured at the chord line, $\mathrm{m}$.

Therefore, the total payload could be estimated by reverting Eq. (1):

$$
Q=\frac{f_{x} \cdot H \cdot L}{[x \cdot(L-x)]}-\frac{1}{2} q \cdot L-\frac{1}{2} q_{2} \cdot L-\frac{1}{2}\left(q_{1}-q_{2}\right) \cdot x
$$




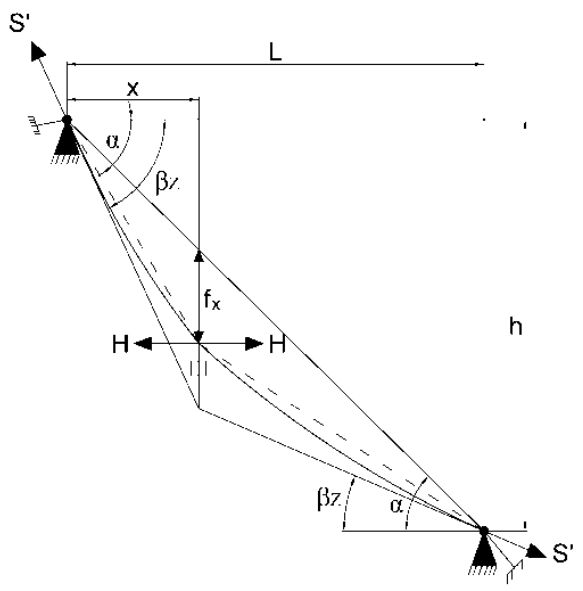

Fig. 3. Adopted scheme of the cable sag due to transportedload [8]

The dataset recorded by the GNSS sensor was postprocessed with Mobile Mapper Office into a shapefile, projected in WGS84 UTM32 coordinate system, that included coordinates $(x, y, z)$ and the time $(0.5 \mathrm{~Hz})$ of each acquired point. In this way, the carriage movements could be described also in terms of position and speed, giving support to the study of work cycles and work elements according already established approaches [5]. Within each working cycle, only the data referred to the loaded carriage moving to the yarding point were isolated and used in the analysis. Then, the carriage position was expressed into local coordinates assuming the tower yarder position as the origin of coordinates. This calculation was based on the Pythagoras theorem applied to the UTM metric coordinate difference between each recorded point and the reference point. The maximum distance from the reference point was assumed as the cycle yarding distance.

Then, the chord line connecting the top of the yarding tower and the base of the anchor tree was retraced as well. The main span returned a horizontal length $\mathrm{L}$ equal to $419 \mathrm{~m}$ and an average slope of $28 \%$. In this way, it was possible to calculate the point-by-point skyline deflection $f_{x}$ by subtracting the elevation of the carriage measured by the GPS from the elevation of the geometrical chord.

Even if the survey was conducted in ideal weather conditions, part of the data was characterized by anomalous recording peaks and instrumental noises. These phenomena were results from sudden shaking of the carriage in case of semi-suspended loads, as well as skyline vertical fluctuations derived from the oscillating the carriage in case of fully suspended loads. To overcome the first issue, an additional equivalent dataset (named "smoothed data") was created, in which deflection original data (hereafter named "raw data") were smoothed using a moving average filter with a time window of 5 samples. The second issue was succeeded by a two-step data elaboration:

- The data of all cycles were categorized into two tables composed of 5 and 15 meters-distance classes taking as the effective deflection the average deflection measured within each class.

- The dataset obtained from each single cycle was split into three sub-datasets. To do so, the maximum distance from the yarding point $(d=L-x)$ reached by the carriage within each cycle was divided into three portions, obtaining three thresholds of distances: next to the felling area (FA), the central portion of the travel (CT), where deflections are minimally influenced by the above-mentioned noises, in proximity to the landing area (LA). For each of three "distance-related" datasets the average of the entire sub-dataset was calculated, as well as the $1^{\text {st }}, 2^{\text {nd }}, 3^{\text {rd }}$ and $4^{\text {th }}$ quartiles.

\section{Results and discussion}

During the field observation26working cycles have been carried out and analyzed to collect outputs related to the deflection occurred to the skyline at different distances. However, statistics and the model have been developed using 13 cycles out of 26 . In fact, the selected cycles turned out to be a sufficient number to develop the model, since the rest of the dataset was not suitable due to GNSS signal corruption or incomplete collection of the tensile force values. Log extraction was concentrated in proximity to the tail hold, a condition that guaranteed an almost complete travel of the carriage 
along the entire span as show in Fig. 4. Table 1 lists the characteristics of the sub-datasets realized for the evaluation of the presented approach. Three distance classes have been formed considering a similar number of data populating each distance class dataset. The number of classes in the felling area changed according to the felling distance observed for each working cycle. Analyses have been carried out on both raw and smoothed datasets.

Table 1

Definition of distance classes: range of distance from tower-yarder $(d)$ and from upper end $(x)$ and number of classes per range (\#) and number of data samples (n)

\begin{tabular}{|c|c|c|c|c|c|}
\hline Distance class & Areas & $\boldsymbol{d}, \mathbf{m}$ & $\boldsymbol{x}=\boldsymbol{L}-\boldsymbol{d}, \mathbf{m}$ & \# of classes per area & $\boldsymbol{n}$ \\
\hline \multirow{2}{*}{ 5-m class } & FA & $240-390$ & $0-120$ & $8-33$ & 260 \\
\cline { 2 - 6 } subdivision & CT & $135-240$ & $120-225$ & 21 & 269 \\
\cline { 2 - 6 } & LA & $0-135$ & $225-390$ & 21 & 269 \\
\hline \multirow{2}{*}{$\begin{array}{c}\text { 15-m class } \\
\text { subdivision }\end{array}$} & FA & $240-390$ & $0-120$ & $5-10$ & 100 \\
\cline { 2 - 6 } & CT & $135-240$ & $120-225$ & 7 & 91 \\
\cline { 2 - 6 } & LA & $0-135$ & $225-390$ & 8 & 104 \\
\hline
\end{tabular}

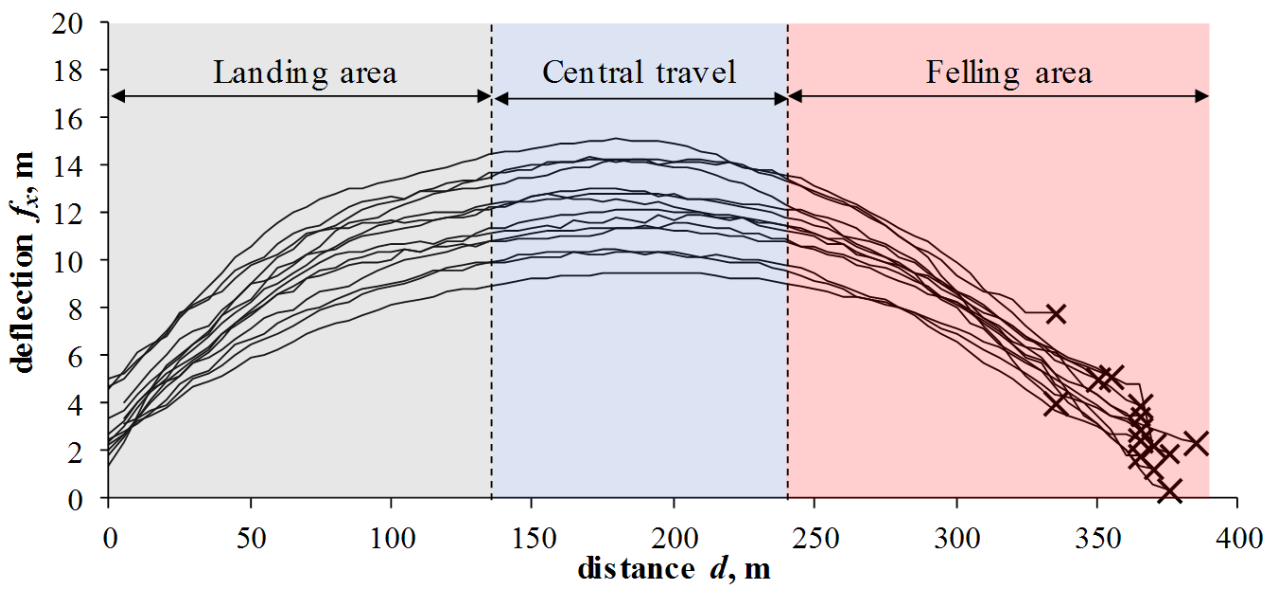

Fig. 4.Measured deflection $f_{x}$ vs. distance $d$

Fig. 5 and Fig. 6 show the results from the 5-m classification, whereas Fig. 7 and Fig. 8 report the results obtained from the $15-\mathrm{m}$ distance classification. Results are plotted following the subdivision of the span into the three above-mentioned class. It emerges that the worthiest outcomes were obtained within the CT threshold. The linear regressions built over the average and maximum values of the estimated payload with respect to the actual measured payload allowed to obtain the highest determination factor $\left(R^{2} \geq 0.73\right)$, independently from the distance classification and smoothing of data. This can be expected as the load in this specific range was generally fully suspended. In FA area correlation is still acceptable and the decreasing efficiency of the model may be due to the partial skidding of the tree at the beginning of the inhaul that occurred on most cases. In this case, smoothing proved to be effective raising the $R^{2}$ from $\geq 0.17$ to $\geq 0.40$. Finally, in LA area, the estimated payload is generally poorly correlated with the actual measured values.

As reported above, the analytical model did not include the reduction of applied load on the cable due to the skidding of the logs where the clearance with respect to the terrain was not sufficient to guarantee fully suspension of the load. Applying the reduction coefficients valid for semi-suspended loads may provide a better fitting in both LA and FA cases.

The differences between the field observations and the analytical prediction were analyzed at each work cycle and described through the mean absolute error (MAE), the root mean square error (RMSE) and its coefficient of variation, calculated as RMSE divided by the measured payload recorded for each cycle as shown in Table 2. Comparing raw and smoothed datasets it appears that the smoothing operation produced no noteworthy improvements in the CT range. Considerably better results were obtained applying such operation in the FA range whereas no improvements were observed in the LA ranges. Therefore, such method may be related to those sections of the cable path that mostly show peaks and disturbed signal. 


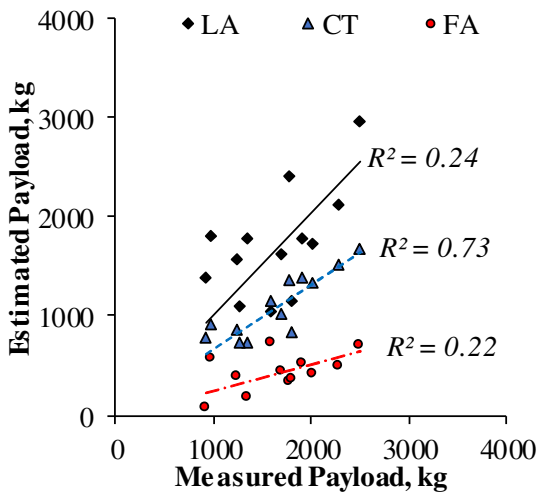

Fig. $5.5 \mathrm{~m}$ class - Average values

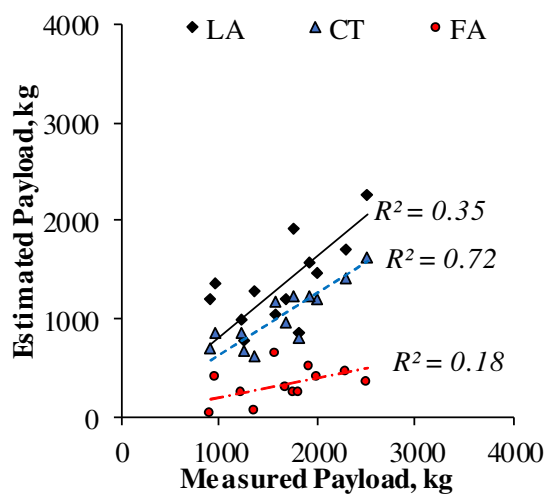

Fig. 7. 15m class - Average values

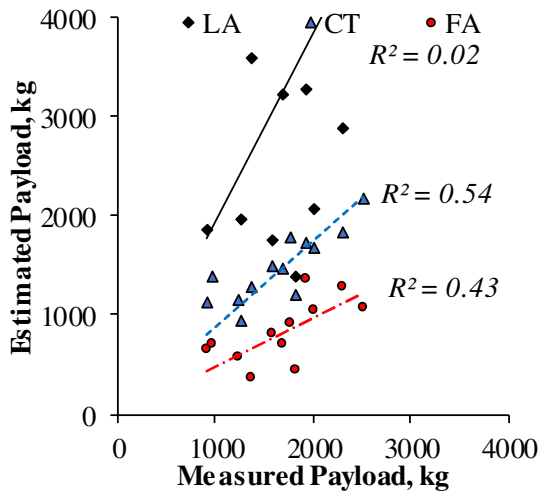

Fig. $6.5 \mathrm{~m}$ class - Max values

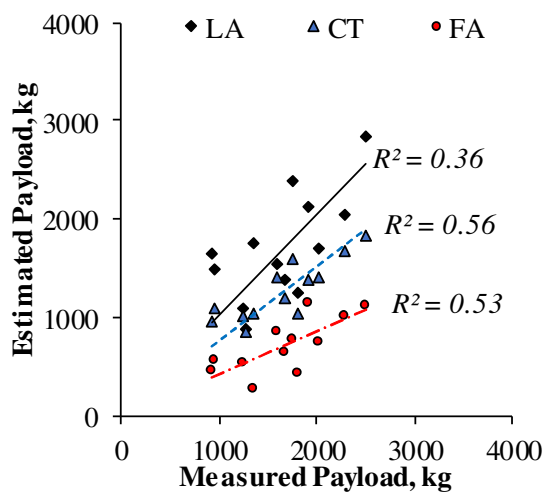

Fig. $8.15 m$ class - Max values

Payload estimation results

\begin{tabular}{|c|c|c|c|c|c|c|c|}
\hline Range & Dist. Class & Dataset & Percentile & MAE (kN) & RMSE (kN) & $\operatorname{COV}(\%)$ & $\mathbf{R}^{2}$ \\
\hline \multirow{8}{*}{ Landing area } & \multirow{4}{*}{$5 \mathrm{~m}$} & \multirow[t]{2}{*}{ Raw } & Average & 402 & 456 & $28 \%$ & 0.24 \\
\hline & & & Max & 1688 & 2171 & $132 \%$ & 0.02 \\
\hline & & \multirow[t]{2}{*}{ Smoothed } & Average & 1061 & 1153 & $70 \%$ & 0.05 \\
\hline & & & Max & 7197 & 7514 & $458 \%$ & 0.14 \\
\hline & \multirow{4}{*}{$15 \mathrm{~m}$} & \multirow[t]{2}{*}{ Raw } & Average & 1373 & 1434 & $87 \%$ & 0.35 \\
\hline & & & Max & 1716 & 1792 & $109 \%$ & 0.36 \\
\hline & & \multirow[t]{2}{*}{ Smoothed } & Average & 2293 & 2321 & $141 \%$ & 0.01 \\
\hline & & & Max & 4438 & 4506 & $275 \%$ & 0.02 \\
\hline \multirow{8}{*}{$\begin{array}{l}\text { Central } \\
\text { portion of } \\
\text { travel }\end{array}$} & \multirow{4}{*}{$5 \mathrm{~m}$} & \multirow[t]{2}{*}{ Raw } & Average & 551 & 605 & $37 \%$ & 0.73 \\
\hline & & & Max & 266 & 313 & $19 \%$ & 0.54 \\
\hline & & \multirow[t]{2}{*}{ Smoothed } & Average & 520 & 579 & $35 \%$ & 0.73 \\
\hline & & & Max & 242 & 291 & $18 \%$ & 0.43 \\
\hline & \multirow{4}{*}{$15 \mathrm{~m}$} & \multirow[t]{2}{*}{ Raw } & Average & 1045 & 1087 & $66 \%$ & 0.72 \\
\hline & & & Max & 1281 & 1314 & $80 \%$ & 0.56 \\
\hline & & \multirow[t]{2}{*}{ Smoothed } & Average & 1055 & 1101 & $67 \%$ & 0.71 \\
\hline & & & Max & 1342 & 1373 & $84 \%$ & 0.43 \\
\hline \multirow{8}{*}{ Felling area } & \multirow{4}{*}{$5 \mathrm{~m}$} & \multirow[t]{2}{*}{ Raw } & Average & 1245 & 1306 & $78 \%$ & 0.22 \\
\hline & & & Max & 888 & 957 & $57 \%$ & 0.43 \\
\hline & & \multirow[t]{2}{*}{ Smoothed } & Average & 1302 & 1365 & $82 \%$ & 0.17 \\
\hline & & & Max & 962 & 1021 & $61 \%$ & 0.47 \\
\hline & \multirow{4}{*}{$15 \mathrm{~m}$} & \multirow[t]{2}{*}{ Raw } & Average & 320 & 368 & $22 \%$ & 0.18 \\
\hline & & & Max & 665 & 739 & $44 \%$ & 0.53 \\
\hline & & \multirow[t]{2}{*}{ Smoothed } & Average & 194 & 244 & $15 \%$ & 0.40 \\
\hline & & & Max & 562 & 660 & $39 \%$ & 0.56 \\
\hline
\end{tabular}


The different amplitude of the distance classes produced contrasting results. Lower COV values (i.e. a higher precision of the model) were obtained for the 5-m distance class in the CT area. On the opposite, a conspicuous improvement was occurred in the FE area when switching to the $15 \mathrm{~m}$ distance class.

Nonetheless, a general common trend can be observed. In fact, the LA distance class produced the worst outcomes independently from the smoothing of the sampled data and the amplitude of the segments in which the distance was subdivided. CT range produced the best results due to the presence of "ideal conditions" in the skyline stretch: fully suspended load and quite constant carriage speed. Lastly, the FA distance class produced an underestimation of the derived payload partially improved, using wider amplitude of segments and the use of smoothing algorithms.

\section{Conclusions}

The use of GNSS skyline deflection data acquisition coupled with measurements of the tensile forces in the cable was found to be a reliable system of tools for an indirect mass assessment of loads during yarding operations. A reasonably high accuracy in estimating the actual payload $\left(R^{2} \geq 0.73\right)$ was obtained in fully suspended loading conditions which occurred in the central part of the cable span. Filtering of signal peaks according to moving average algorithms, as well as adaptation of the amplitude over which analytical values were computed allowed to compensate the carriage vertical oscillations and extend the precision of the model also in proximity to the felling area $\left(R^{2} \geq 0.43\right)$. In further works, effects of partial suspension should be included in the analytical payload calculation to extend the use of the deflection assessment in areas with reduced clearance from the ground.

\section{References}

[1] Figorilli S., Antonucci F., Costa C., Pallottino F., Raso L., Castiglione M., et al. A blockchain implementation prototype for the electronic open source traceability of wood along the whole supply chain. Sensors, vol. 18, 2018.

[2] Cadei A., Mologni O., Röser D., Cavalli R., Grigolato S. Forwarder Productivity in Salvage Logging Operations in Difficult Terrain. Forests, vol. 11:341, 2020.

[3] Gallo R., Grigolato S., Cavalli R., Mazzetto F. GNSS-based operational monitoring devices for forest logging operation chains. Journal of Agricultural Engineering, vol.44, 2013

[4] Pierzchała M., Kvaal K., Stampfer K., Talbot B. Automatic recognition of work phases in cable yarding supported by sensor fusion. International Journal of Forest Engineering, vol. 29, 2017, pp. $12-20$.

[5] Lezier A., Cadei A., Mologni O., Marchi L., Grigolato S. Development of a device based on a open-source electronics platform for the monitoring of cable-logging operations. Engineering for Rural Development, 2019, pp.72-77.

[6] Marchi L., Mologni O., Trutalli D., Scotta R., Cavalli R., Montecchio L., et al. Safety assessment of trees used as anchors in cable-supported tree harvesting based on experimental observations. Biosystems Engineering,vol. 186, 2019, pp.71-82.

[7] Pyles M.R., Anderson J.W., Stafford S.G. Capacity of Second-Growth Douglas-fir and Western Hemlock Stump Anchors for Cable Logging. Journal of Forest Engineering, vol. 3, 1991, pp. 2937.

[8] Samset I. Winch and cable systems. Dordrecht: Springer, 1985. 540 p.

[9] Dupire S., Bourrier F., Berger F. Predicting load path and tensile forces during cable yarding operations on steep terrain. Journal of Forest Research, vol. 21, 2016, pp. 1-14.

[10] Gallo R., Mazzetto F. A solution for indirect mass assessment of timber during fully suspended yarding operations. 2019 IEEE International Workshop on Metrology for Agriculture and Forestry, 2019, pp. 333-338.

[11] Giordano G. Tecnologia del legno. La materia prima. vol. I. Torino: UTET, 1981. 1256 p.

[12] Spinelli R., Nati C., Magagnotti N. Recupero di biomassa. Sherwood - AlcuneUtilizzazioni in BoschiAlpini, vol. 119, 2006. 